\title{
Erratum zu: Rohstoffpotenzial von MVA-Rostaschen für Metallrückgewinnung und Karbonatisierung
}

\section{Kerstin Pfandl · Gerhard Stockinger • Daniel Höllen · Roland Pomberger}

Online publiziert: 20. September 2018

(c) Springer-Verlag GmbH Austria, ein Teil von Springer Nature 2018

\section{Erratum zu:}

Österr Wasser- und Abfallw 2018

https://doi.org/10.1007/s00506-018-

0464-x

Statt Abb. 9 wurde irrtümlicherweise Abb. 7 wiederholt abgedruckt. In Abb. 9 ist die Verteilung der potenziell kritischen (PKE) und der kritischen Elemente (KE) auf die Outputströme der Fe/NE-Scheidung 6,3-10 mm und $10-16 \mathrm{~mm}$ in Massenprozent zu sehen, während in Abb. 7 die chemische $\mathrm{Zu}$ sammensetzung der Schwerfraktion $0-16 \mathrm{~mm}$ in Milligramm pro Kilogramm dargestellt wird.

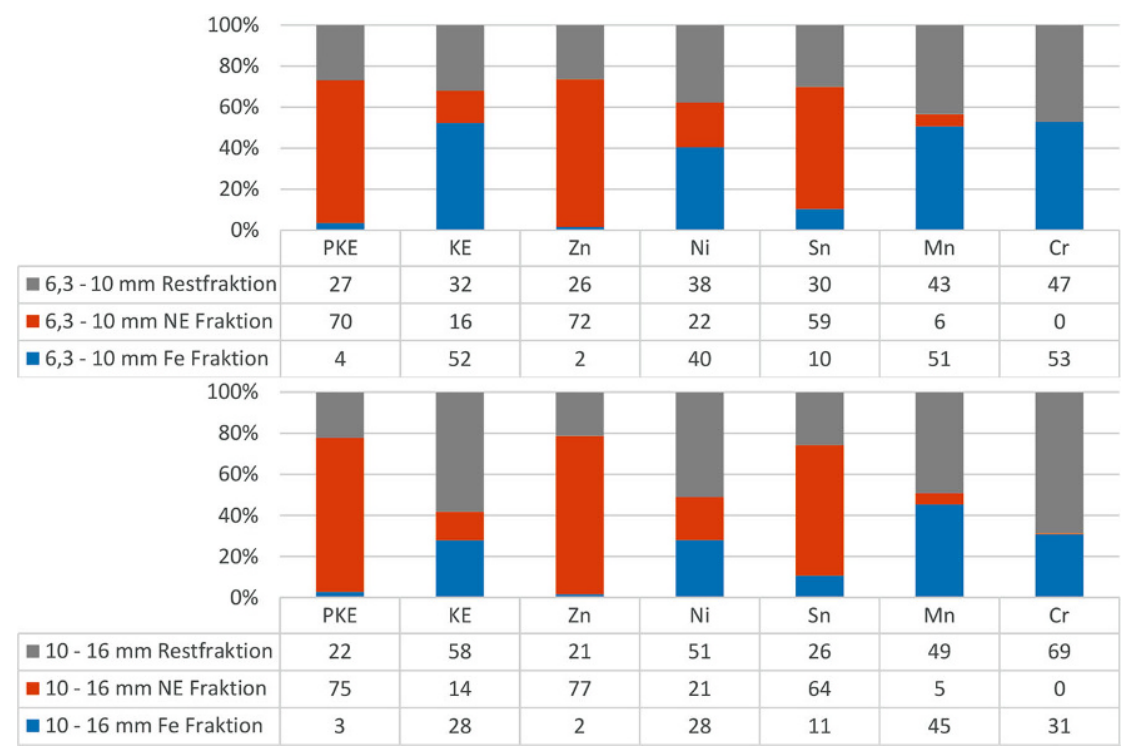

Abb. 9 Verteilung der potenziell kritischen (PKE) und der kritischen Elemente (KE) auf die Outputströme der Fe/NE-Scheidung 6,3-10 mm und 10-16 mm in Massenprozent

Dipl.-Ing. K. Pfandl (殴 .

Ass.-Prof. Dipl.-Min. Dr. D. Höllen .

Univ.-Prof.Dipl.-Ing.Dr.mont. R. Pomberger

Lehrstuhl für

Abfallverwertungstechnik

und Abfallwirtschaft,

Montanuniversität Leoben,

Franz-Josef-Straße 18, 8700 Leoben,

Österreich

kerstin.pfandl@unileoben.ac.at

\section{G. Stockinger, MEng}

Brantner Environment Group GmbH,

Dr.-Franz-Wilhelm-Straße 1, 3500 Krems an der Donau, Österreich
Die Online-Version des Originalartikels ist unter https://doi.org/10.1007/s00506018-0464-x zu finden. 